\title{
Diversity and evolution of pollinator rewards and protection by Macaranga (Euphorbiaceae) bracteoles
}

\author{
Eri Yamasaki $\cdot$ Atsushi Kawakita $\cdot$ Shoko Sakai
}

Received: 25 March 2014/ Accepted: 2 December 2014

(C) Springer International Publishing Switzerland 2014

\begin{abstract}
Flowering plants have modified their floral organs in remarkably diverse ways to optimize their interaction with pollinators. Although floral organs represent a major source of floral diversity, many plants also use extrafloral organs, such as bracts and bracteoles, in interacting with pollinators; however, the evolutionary dynamics of nonfloral organs involved in pollination are poorly studied. The genus Macaranga is characterized by protective mutualisms with ants that potentially interfere with pollinators on flowers. Macaranga flowers lack perianths and, notably, bracteoles serve the dual function of rewarding pollinators and protecting them from guarding ants; in one group of species, bracteoles provide a nectar reward to generalist pollinators, while in another group, bracteole "chambers" protect thrips or hemipteran pollinators that use these structures as feeding and breeding sites. We examined the diversity and evolutionary dynamics of inflorescence morphology in Macaranga, focusing on bracteoles. We recognized three inflorescence types based on examination of herbarium materials: Discoid-gland, which possess disc-shaped glands on the bracteole surfaces (including all the generalist-pollinated species); Enclosing, in which bracteoles cover flowers (including all the thrips- and hemipteran-pollinated species); and Inconspicuous, in which bracteoles are small, narrow or absent. Ancestral state reconstruction indicated that inflorescence morphologies have changed multiple times in the genus. These findings suggest that morphological changes in non-floral characters (bracteoles) of Macaranga species have occurred as frequently as in the floral structures of many flowering plants. The multiple evolutions of the Enclosing
\end{abstract}

Electronic supplementary material The online version of this article (doi:10.1007/s10682-014-9750-7) contains supplementary material, which is available to authorized users.

E. Yamasaki · A. Kawakita · S. Sakai

Center for Ecological Research, Kyoto University, Hirano 2-509-3, Otsu, Shiga 520-2113, Japan

E. Yamasaki $(\bowtie)$

Institute of Evolutionary Biology and Environmental Studies, University of Zurich,

Winterthurerstrasse 190, 8057 Zurich, Switzerland

e-mail: yamasakiebi@gmail.com 
bracteoles, which protect pollinators, might have been facilitated by pollination interference from mutualistic ants.

Keywords Ant-plants - Euphorbiaceae $\cdot$ Extrafloral nectary $\cdot$ Hemipteran pollination · Macaranga $\cdot$ Thrips pollination

\section{Introduction}

Flowering plants exhibit enormously diverse floral traits, many of which are useful for animal pollination (Ollerton et al. 2011). For example, showy perianths and odors can efficiently attract pollinators, and nectars, oils, resins, and other floral secretions can reward pollinators (Fægri and van der Pijl 1979). Therefore, biologists have studied how flower visitors influence the evolution of floral traits in various plant groups by combining phylogenetic relationships among focal plants, and their floral traits and pollination systems (Johnson et al. 1998; Beardsley et al. 2003; Whittall and Hodges 2007; Wilson et al. 2007; Okuyama et al. 2008; Kawakita and Kato 2009; Sakai et al. 2013). Overall, evidence suggests that the same pollination systems have evolved repeatedly among plant groups, altering floral traits and confirming their flexibility.

Although both floral and extrafloral organs are used for attracting and/or rewarding pollinators, floral organs such as petals, sepals, and nectaries within flowers play more important roles in pollination than extrafloral organs in most flowering plants. However, in some plant species, especially in those which have lost conspicuous petals or sepals, extrafloral organs are more important for interactions with pollinators; in most of these cases, bracts and bracteoles play major roles (Ehrenfeld 1979; Armbruster 1997; Wragg and Johnson 2011; Bröderbauer et al. 2012). The roles of bracts or bracteoles have been well described in the pollination systems of the Araceae, and in the Euphorbia, Dalechampia (Euphorbiaceae), and some Cyperus (Cyperaceae) species (Ehrenfeld 1979; Armbruster 1997; Wragg and Johnson 2011; Bröderbauer et al. 2012), but it is unclear whether bracts or bracteoles in these plants change as flexibly as floral organs, or are under similar evolutionary constraints. Some studies have suggested frequent changes in pollination systems without large morphological changes; Armbruster (1993) and Armbruster (1997) reported frequent pollinator reward shifts between resin and pheromone precursors or pollen in Dalechampia, while the structure of bracts, the primary organ used to attract pollinators, remained consistent. In Araceae, evolution of pollinator-trapping chambers that enclose the spadices has occurred at least ten times from inflorescences in which bracts do not cover the spadices completely. However, bract shape does not change drastically in many species in which bracts surround the spadices and form a chamber around the flowers (Bröderbauer et al. 2012).

It has been said that pollinators play important roles in driving plant traits involved in pollination (Whittall and Hodges 2007; van der Niet and Johnson 2012). However, flowers are visited not only by pollinators but also by unfavorable animals, such as florivores, worthless pollinators, or pollinator-excluding animals (primarily ants) (Willmer and Stone 1997; Irwin et al. 2004). These unfavorable visitors can also have a selective effect on floral/inflorescence traits; for example, long corollas exclude insects with short mouthparts, and pendulous flowers exclude all but hovering insects and those with strong legs (Proctor et al. 2006). 
In this study, we investigated the evolution of inflorescence morphologies in the dioecious tree genus Macaranga (Euphorbiaceae), distributed in tropical to subtropical regions (Whitmore 2008). Recent studies have reported two distinct bracteole morphologies in the genus associated with different pollination systems. The first consists of paddleshaped bracteoles with one to several disc-shaped nectaries on the adaxial (upper) surfaces (Fig. 1a; Yamasaki et al. 2013). Pollinator insects visit the inflorescences in search of nectar secreted from the nectaries. The number and size of the bracteoles do not differ between male and female inflorescences. The second consists of bracteoles enclosing flowers associated with pollination by thrips, Dolichothrips spp. (Phlaeothripidae) or by hemipterans of the Anthocoridae and Miridae (Fig. 1b; Moog et al. 2002; Ishida et al. 2009; Fiala et al. 2011). The pollinators breed in bracteole chambers and feed on trichomeand/or ball-shaped nectaries on the adaxial surfaces of the bracteoles. Although the shape is similar between male and female inflorescences, the bracteoles are stouter and fewer in number in female than in male inflorescences (Davies and Ashton 1999).

Macaranga is well known for its protective mutualisms with ants. Most of the ca. 260 species in the genus possess extrafloral nectaries and/or food bodies (nourishing small particles) on leaves and potentially attract ants that can exclude herbivores from flowers (Whalen and Mackay 1988; Fiala and Maschwitz 1991; Mackay and Whalen 1991; Whitmore 2008). On the other hand, ca. 30 species offer not only foods for ants but also nesting sites for them (Davies et al. 2001). In this paper, we call these species "ant-plants." The ant-plant Macaranga species are intensely protected by the almost species-specific resident ants, compared to species that are facultatively protected by ants attracted to extrafloral nectaries and/or food bodies (Quek et al. 2004; Itioka 2005). While ant-plant Macaranga species are pollinated by Dolichothrips spp. (Fiala et al. 2011), our previous study indicated that pollinator thrips are not excluded by the guard ants (Yamasaki et al. 2014). This may be because pollinators are protected from the guard ants by bracteoles (Fiala et al. 2011; Yamasaki et al. 2014); although ant guards are often seen on the surface of the inflorescences, we have never observed the guard ants crawling into the chambers, where pollinator thrips spend most of their lifetime, maybe because the gaps of the bracteoles are too narrow for the ants.

While some previous studies have examined the evolution of inflorescence morphology in Macaranga (Davies 2001; Fiala et al. 2011), they mainly focused on the sister sections Pachystemon and Pruinosae, which have flower-enclosing bracteoles, no clear overview of the evolutionary pattern in the genus has been elucidated. The aim of this study was to
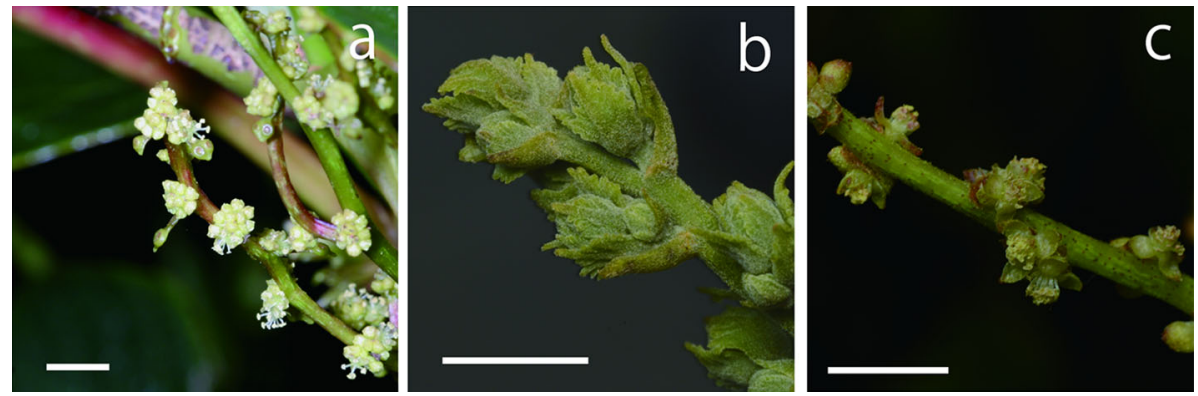

Fig. 1 Examples of species exhibiting the three inflorescence types, categorized based on bracteole morphology: a Macaranga sinensis (Discoid-gland type), b Macaranga gigantea (Enclosing type), and c Macaranga coriacea (Inconspicuous type) (not included in the phylogeny). Scale bar $1 \mathrm{~cm}$ 
examine whether inflorescence morphologies have changed repeatedly and, if so, whether the repeated evolution is related to interacting animals such as pollinators and bodyguard ants in Macaranga. For this purpose, we first examined interspecific variation in inflorescence morphologies and estimated pollination systems of each morphology type by examining the inflorescence characteristics and previous pollination studies in Macaranga. Next, we mapped the inflorescence types on a molecular phylogenetic tree and estimated ancestral inflorescence morphologies to examine whether inflorescence morphologies have repeatedly changed in Macaranga.

\section{Materials and methods}

Observation of inflorescence/floral morphologies

We observed the inflorescences of dry specimens of 53 taxa in the genus Macaranga (52 species and one variety) in herbaria (Royal Botanic Gardens, Kew (K), Leiden Naturalis Biodiversity Center (L), Kyoto University (KYO) and Forest Department, Sarawak (SAR)). We also obtained morphological data for Macaranga lamellata and Macaranga umbrosa from Fiala et al. (2011). We recorded (1) the presence/absence of disc-shaped glands on bracteole surfaces, (2) internode distances between adjacent bracteoles, (3) length, and (4) width of bracteoles in male specimens, and (5) style length in female specimens (Fig. 2). Traits (1)-(4) were not measured in female specimens because those with bracteoles were absent in many of the species, while most of the bracteoles in male inflorescences remained. For each trait, we looked at two to five samples from each of one to five specimens. For trait (1), we judged disc-shaped glands to be present when at least one bracteole possessed them, and we determined that specific taxa possessed the glands if they occurred in at least one specimen. The presence/absence of the glands was consistent

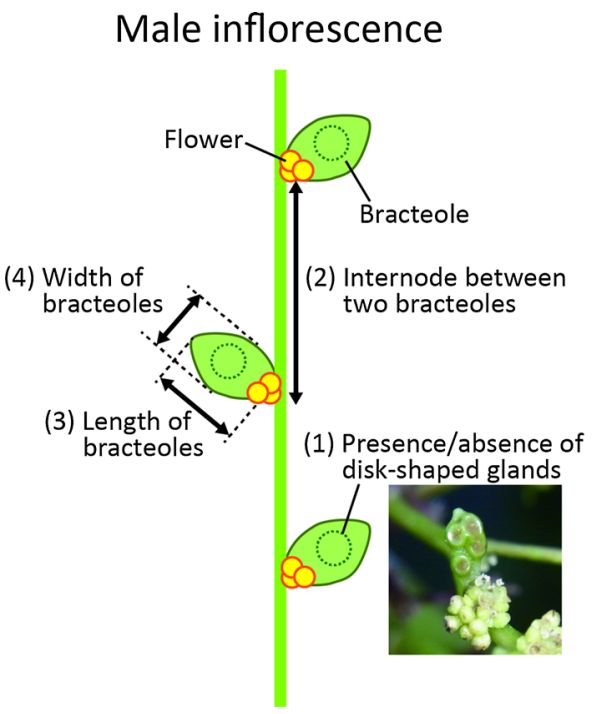

\section{Female inflorescence}

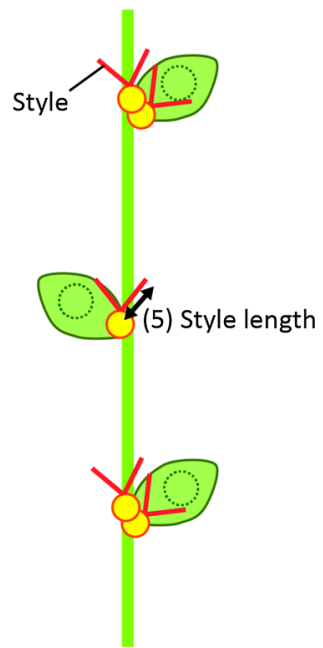

Fig. 2 The inflorescence/floral traits investigated. See (1)-(5) in the "Observation of inflorescence/floral morphologies" section of "Materials and methods" 
among specimens in most species, with the exception of Macaranga denticulata. Some specimens of this species lack disc-shaped glands on their bracteoles, but in all other respects, their bracteoles were similar to those of other specimens. Thus, we regarded it as a species with disc-shaped glands. For quantitative traits (2)-(5), average values were calculated for each specimen and averaged across specimens to obtain species values.

To determine which traits to use in categorizing inflorescence morphologies, we examined the differences in inflorescence morphologies among the species by principal component analysis (PCA) using Z-score standardized values of the four quantitative traits [traits (2)-(5)]. Thirty-two taxa in which all four variables were available were included in the analysis. We used the prcomp function in R 3.0.2 (R Development Core Team 2013). The first principal component (PC 1) clearly separated species that did not contain discshaped glands into two groups, and bracteole length and width were major components (see "Results" section). Therefore, we classified all 55 taxa into three inflorescence types based on the presence/absence of disc-shaped glands, and bracteole shape and size (see "Results" section). Style length was not used because we were unable to measure it in many species, mostly due to a lack of specimens containing flowering female inflorescences.

Molecular phylogenetic analysis

We constructed a molecular phylogeny based on the DNA sequence and indel data on one plastid (trnL-F) and three nuclear markers (ITS, ncpGS, and phyC) of 59 taxa in the genus Macaranga using species of the related genus Mallotus (Euphorbiaceae) as outgroups (Mallotus griffithianus, Mallotus claoxyloides, and Mallotus paniculatus). Alignment and indel data for all taxa other than Macaranga sinensis were acquired from Kulju et al. (2007); those of $M$. sinensis were obtained via the following procedures. First, DNA was extracted from silica gel-dried leaves following a modified CTAB procedure (Doyle and Doyle 1987; Okuyama and Kawakita 2012). Regions were amplified by different primer pairs (Kulju et al. 2007). Polymerase chain reaction (PCR) amplifications were carried as follows: initial denaturation step at $94{ }^{\circ} \mathrm{C}$ for $5 \mathrm{~min} ; 30$ cycles of $94{ }^{\circ} \mathrm{C}$ for $30 \mathrm{~s}, 50{ }^{\circ} \mathrm{C}$ for $30 \mathrm{~s}$, and $72{ }^{\circ} \mathrm{C}$ for $1 \mathrm{~min}$; and a final extension at $72{ }^{\circ} \mathrm{C}$ for $7 \mathrm{~min}$. Products were sequenced on an ABI 3100 automated sequencer using BigDye chain termination chemistry (Applied Biosystems, Foster City, CA, USA), and obvious sequence errors were manually corrected using MEGA 5.05. Indel information was incorporated based on Kulju et al. (2007). A phylogenetic tree was constructed by Bayesian inference methods using MrBayes version 3.2 (Ronquist and Huelsenbeck 2003). The substitution models were chosen separately for each marker based on Akaike Information Criterion using Kakusan 4 (Tanabe 2011) as follows: GTR+G for trnL and ITS and HKY85+G for $n c p G S$ and $p h y C$. We employed the binary model for gap characters (Ronquist and Huelsenbeck 2003). Two independent runs for four Markov chains were conducted for four million generations, and the tree was sampled every 100 generations. The first 4,001 trees were discarded as burnin. A majority-rule consensus tree was constructed from the remaining 36,000 trees.

Reconstruction of ancestral inflorescence morphologies

To investigate how inflorescence type has shifted in the genus, we estimated ancestral inflorescence morphologies (the inflorescence morphology of each node) using 1,000 trees randomly chosen from the Bayesian phylogenetic analysis. Inflorescence morphologies of the outgroups are not included in the analysis. The Markov chain Monte Carlo method (Ronquist 2004) was applied for this analysis using the BayesMultiState function in 
BayesTraits (Pagel and Meade 2006). The reverse jump hyper prior function with a gamma prior of $0,10,0,10$ (minimum and maximum of priors for both mean and variance parameters) was used. Rate deviation was set to 50 to achieve the recommended $20-40 \%$ acceptance rates. Inflorescence morphology types were treated as categorical variables with three states (Fig. 1; see "Results" section). Alternative ancestral states were compared on 49 nodes with $>0.5$ posterior probabilities using the 'fossil' (fixing) command. Because harmonic means in the analyses can be unstable (Pagel and Meade 2006), we ran the analyses five times to check the consistency of the results. Bayes Factors (2 [ $\log ($ harmonic mean of model 1) $-\log ($ harmonic mean of model 2) $])>5$ indicated strong evidence of support for the best model (Pagel et al. 2004).

\section{Results}

Observation of inflorescence/floral morphologies

Based on the PCA results, inflorescence types were classified into three categories using bracteole shape and size and the presence/absence of disc-shaped glands: Discoid-gland, Inconspicuous, and Enclosing (Fig. 1; Supplemental Table 1). In the PCA results, the first and second principal components (PC 1 and PC 2) contributed $54.1 \%$ and $24.6 \%$ of the total variance of the measured data, respectively (Table 1). Bracteole size (length and width) and style length had substantial loading in PC 1 (Table 1; Fig. 3). PC 1 distinctly separated species not possessing disc-shaped glands into two groups: one with relatively large bracteoles and short styles, and one with small bracteoles and long styles. PC 2 mainly represented internode distances between bracteoles and bracteole length, and some species with disc-shaped glands had extremely low values. The two groups distinguished by PC 1 were not represented by PC 2 .

The three categories are defined as follows based on the PCA and presence/absence of disc-shaped glands:

\begin{tabular}{cll}
\hline (1a) & Disc-shaped glands on the bracteole surfaces present & Discoid-gland \\
(1b) & Disc-shaped glands on the bracteole surfaces absent & (2) \\
(2a) & $\begin{array}{l}\text { Bracteoles very small (length and width }<1.6 \mathrm{~mm} \text { ) or narrow } \\
(\text { length/width }>1.8) \text {, or absent }\end{array}$ & Inconspicuous \\
(2b) & Bracteoles relatively large, enclosing flower clusters & Enclosing \\
\hline
\end{tabular}

We also observed fresh inflorescences of 11 species in which all three inflorescence types were represented. The shape did not differ between dry specimens and fresh

Table 1 The proportion of variance and factor loadings of principal components analysis axes using four inflorescence traits

\begin{tabular}{llc}
\hline & PC 1 & PC 2 \\
\hline Proportion of variance & $54.11 \%$ & $24.60 \%$ \\
Internode between bracteoles & -0.20 & -0.96 \\
Length of bracteole & -0.61 & -0.26 \\
Width of bracteole & -0.65 & -0.00 \\
Style length & -0.41 & -0.08 \\
\hline
\end{tabular}




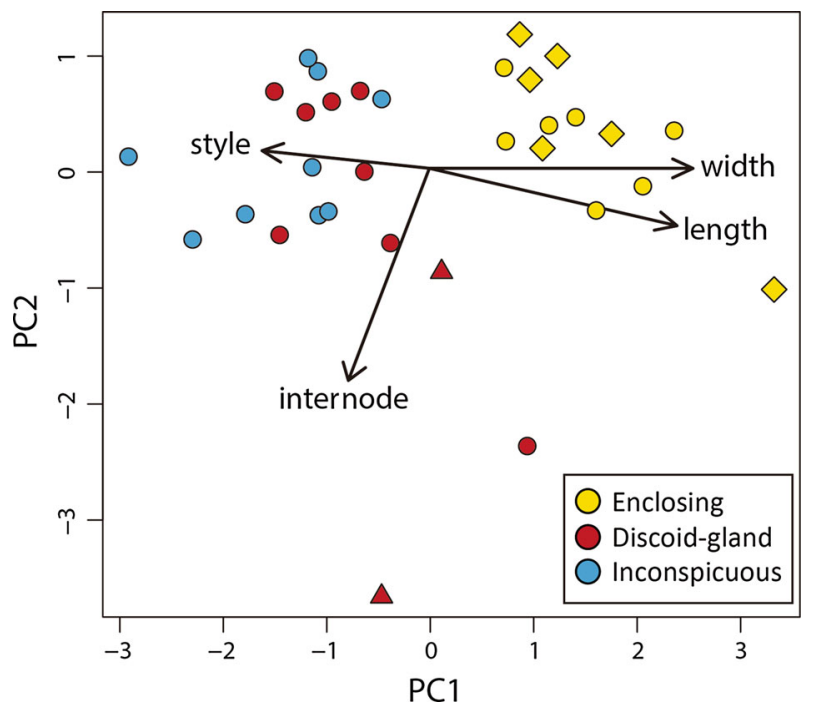

Fig. 3 Scatterplot of the first and second principal components ( $P C 1$ and $P C$ 2) of a principal components analysis (PCA) using four inflorescence and floral traits (internode distances between adjacent bracteoles, lengths and widths of bracteoles, internodes between two bracteoles, and style lengths). Different colors indicate inflorescence types (see text for classifications). Species visited mainly by thrips or hemipterans and those visited by other insects are indicated by diamond and triangle symbols, respectively. The information on flower visitors was obtained from Moog et al. (2002), Ishida et al. (2009), Fiala et al. (2011), and Yamasaki et al. (2013)

inflorescences, although the size was smaller in the dry specimens. All species mainly visited by thrips or hemipterans were of the Enclosing type (Moog et al. 2002; Ishida et al. 2009; Fiala et al. 2011; Figs. 3, 4), as were the ant-plant species (Davies 2001; Davies et al. 2001; Fig. 4). M. sinensis, pollinated by generalist insects attracted to the disc-shaped nectaries on bracteoles (Yamasaki et al. 2013), and M. denticulata and Macaranga indica, whose male inflorescences are mainly visited by generalist insects (bees, flies, wasps, and beetles) (Fiala et al. 2011), were of the Discoid-gland type (Fig. 4).

Molecular phylogenetic analysis

Molecular analysis revealed two well-supported basal clades (B1 and B2) and three crown clades (C1, C2, and C3), as in Kulju et al. (2007), who analyzed the phylogeny by Bayesian and maximum parsimony methods (Fig. 4).

Reconstruction of ancestral bracteole morphologies

All observed species in basal clades B1 and B2 were classified into the Inconspicuous category (Fig. 4). Conversely, we detected all three inflorescence types in the crown clades. No inflorescence type was determined to be monophyletic. Among the 49 focal nodes, six, five, and 14 nodes were strongly supported as Inconspicuous, Discoid-gland, and Enclosing types, respectively (Bayes factors $>$; Fig. 4). When Bayes factor $>5$ is considered to indicate a significant occurrence of the focal inflorescence type, ancestral 


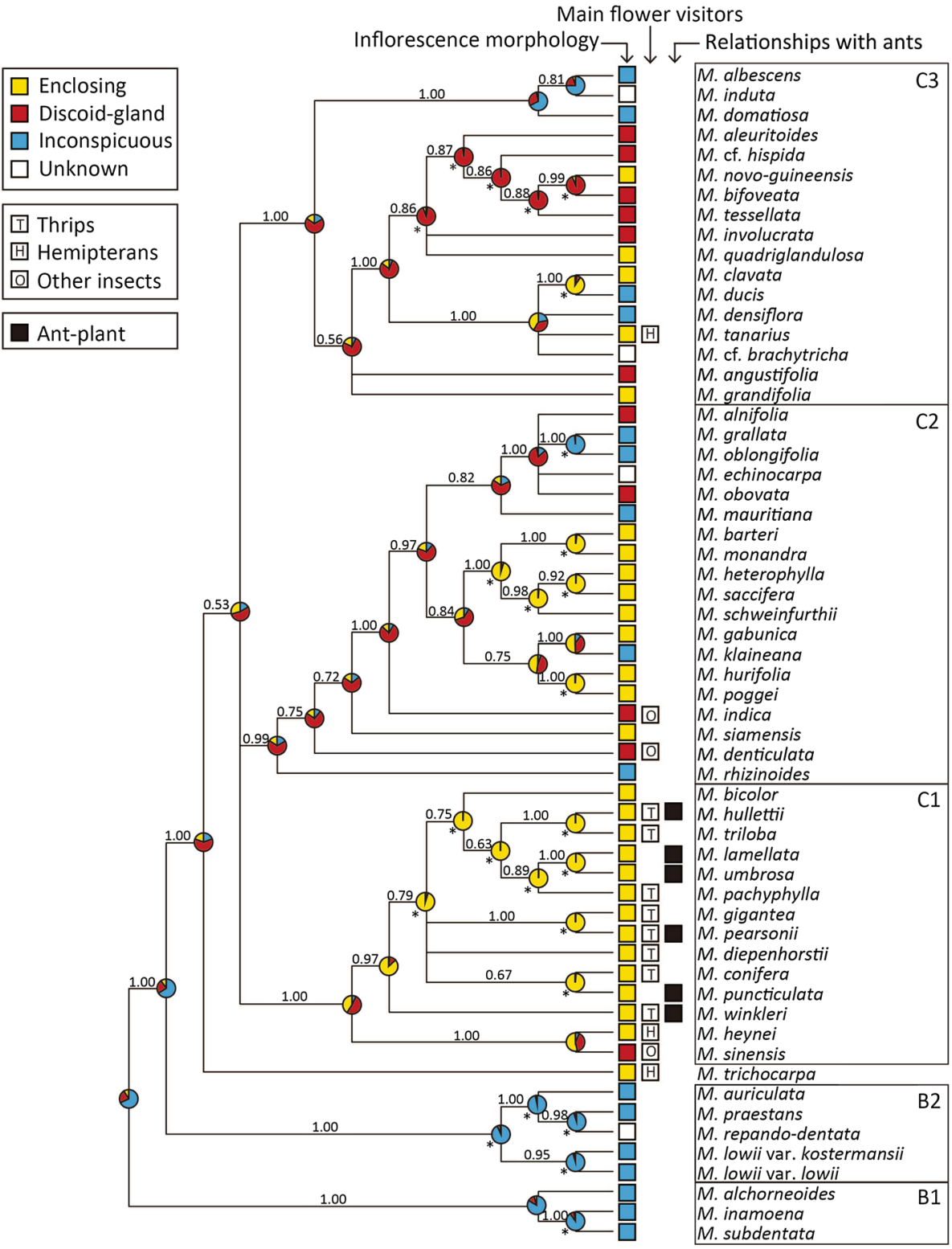

Fig. 4 Phylogenetic tree of Macaranga species constructed with the Bayesian inference method. The pies indicate estimated ancestral morphologies by Bayesian inference methods. Bayes factors $>5$ are indicated with an asterisk. Numbers above branches indicate posterior probabilities of the branches obtained from reconstruction of the tree $(>0.5)$. The mapped information, with the exception of inflorescence morphologies, was obtained from the following literature: main flower visitors, Moog et al. (2002), Ishida et al. (2009), Fiala et al. (2011), and Yamasaki et al. (2013); whether the species are ant-plants, Davies (2001) and Davies et al. (2001). Clade grouping (B1, B2, C1, C2, and C3) was done according to Kulju et al. (2007) 
state reconstruction indicated at least two shifts from the Discoid-gland to the Enclosing type and at least one shift from the Enclosing to the Inconspicuous type (Fig. 4).

\section{Discussion}

All Macaranga species in this study were classified into three inflorescence types based on bracteole morphological characteristics: Discoid-gland, Inconspicuous, and Enclosing (Fig. 1, see "Results" section for detailed characteristics). Considering the morphology and existing pollination studies in Macaranga, we propose that the three types of inflorescence morphology are related to different pollination systems. Because this study lacks empirical pollination surveys for many of the species, we cannot yet test this hypothesis. However, it is often said that floral morphologies are generated by functional groups of similar pollinators (Fægri and van der Pijl 1979; Fenster et al. 2004). Wind may contribute, at least in part, to pollination in the Inconspicuous species, which have exposed flowers, inflorescences that penetrate through the leaf mass, and sometimes extremely long (up to $5 \mathrm{~cm}$ ) styles (Bullock 1994; Culley et al. 2002). We observed that Macaranga vedeliana, with Inconspicuous inflorescences (not included in this study), did not secrete nectar and were wind-pollinated (Yamasaki et al. unpublished data; Supplemental Figure 2).

In Discoid-gland species, the glands on bracteoles, which are located adjacent to flowers, may attract insects for pollination in the manner of M. sinensis, which is pollinated by generalist insects that forage on the disc-shaped nectaries (Yamasaki et al. 2013). Similarly, male inflorescences of two other Discoid-gland species, $M$. denticulata and $M$. indica, are visited by generalist insects such as bees, wasps, flies, and beetles (Fiala et al. 2011). On the other hand, the nectaries on bracteoles may also attract ants, which may exclude pollinators or contribute pollination. Further experimental studies are needed to confirm whether the nectaries on the bracteoles attract pollinators and how the plants avoid disadvantage from ants if the glands also attract ants.

All thrips- or hemipteran-pollinated species (Moog et al. 2002; Ishida et al. 2009; Fiala et al. 2011) were classified as Enclosing species (Fig. 4). Pollination by wind or generalist insects such as bees and flies is unlikely for this inflorescence type because such pollen vectors are impeded by the bracteoles. In addition to providing chambers for pollinators, the bracteoles of the Enclosing type may also physically protect pollinators against their natural enemies, such as ants (Fiala et al. 2011; Yamasaki et al. 2014).

Ancestral state reconstruction indicated at least two shifts from the Discoid-gland to the Enclosing type and at least one shift from the Enclosing to the Inconspicuous type (Fig. 4). Additionally, while direction is ambiguous, among the three inflorescence types, other shifts seem to have occurred several times (Fig. 4). The present study is the first to describe multiple drastic evolutionary changes in extrafloral plant organs.

Repeated evolution of the Enclosing inflorescence type might be due to pollination interference by ants. Because bracteoles can physically separate ants and pollinators on the inflorescences, pollination interference by ants may have selected for the evolution of flower-covering bracteoles that eliminate ants from flowers. Therefore, the flowerenclosing bracteoles in the Enclosing inflorescences may act as "barriers" against pollination-interfering animals (Santamaría and Rodríguez-Gironés 2007). To explore these possibilities, the functions of bracteoles should be examined in Enclosing species from various clades. It would also be instructive to investigate why species with other inflorescence types do not need to exclude guard ants from their flowers. Because ant-plants are likely to have occurred more than once in an Enclosing-type clade (Blattner et al. 2001; 
Davies et al. 2001), the evolution of ant-plants and the development of the Enclosing inflorescences may be related. Not only mutualisms with ants but also the lack of perianths may be related to the multiple evolutions of the Enclosing type; because Macaranga lacks perianths that visually attract generalist pollinators such as bees, specialization for pollination by thrips or hemipterans, which infest the flowers of various plants (Lewis 1973; Wheeler 2001), may have occurred relatively easily.

In conclusion, our study found high variability in bracteole morphology compared with that of flowers. Macaranga species have repeatedly evolved unusual traits involved in pollination, including flower-enclosing bracteoles. The repeated evolution of flowerenclosing bracteoles may indicate a recurring need for floral barriers against bodyguard ants. The genus Macaranga may be a good model for studying the factors underlying the acquisition of floral barriers.

Acknowledgments We are grateful to herbaria of Royal Botanic Gardens, Kew (K), Leiden Naturalis Biodiversity Center (L), Kyoto University (KYO) and Department of Forestry, Sarawak (SAR) for providing Macaranga specimens. This study was financially supported by the Research Institute for Humanity and Nature (Project D-04), Grants-in-Aid No. 21570028 from the Ministry of Education, Culture, Sports, Science and Technology, Japan, to S.S., Grants-in-Aid for JSPS Fellows from the Japan Society for the Promotion of Science (No. 24-1464 to E.Y.), and Kyoto University Global COE program "Formation of a strategic base for biodiversity and evolutionary research: from genome to ecosystem".

\section{References}

Armbruster WS (1993) Evolution of plant pollination systems: hypotheses and tests with the neotropical vine Dalechampia. Evolution 47:1480-1505

Armbruster WS (1997) Exaptations link evolution of plant-herbivore and plant-pollinator interactions: a phylogenetic inquiry. Ecology 78:1661-1672

Beardsley PM, Yen A, Olmstead RG (2003) AFLP phylogeny of Mimulus section Erythranthe and the evolution of hummingbird pollination. Evolution 57:1397-1410

Blattner FR, Weising K, Bänfer G et al (2001) Molecular analysis of phylogenetic relationships among myrmecophytic Macaranga species (Euphorbiaceae). Mol Phylogenet Evol 19:331-344

Bröderbauer D, Diaz A, Weber A (2012) Reconstructing the origin and elaboration of insect-trapping inflorescences in the Araceae. Am J Bot 99:1666-1679

Bullock SH (1994) Wind pollination of neotropical dioecious trees. Biotropica 26:172-179

Culley TM, Weller SG, Sakai AK (2002) The evolution of wind pollination in angiosperms. Trends Ecol Evol 17:361-369

Davies SJ (2001) Systematics of Macaranga Sects. Pachystemon and Pruinosae (Euphorbiaceae). Harvard Pap Bot 6:371-448

Davies SJ, Ashton PS (1999) Phenology and fecundity in 11 sympatic pioneer species of Macaranga (Euphorbiaceae) in Borneo. Am J Bot 86:1786-1795

Davies SJ, Lum SKY, Chan R, Wang LK (2001) Evolution of myrmecophytism in western Malesian Macaranga (Euphorbiaceae). Evolution 55:1542-1559

Doyle JJ, Doyle JL (1987) A rapid DNA isolation procedure for small quantities of fresh leaf tissue. Phytochem Bull 19:11-15

Ehrenfeld JG (1979) Pollination of three species of Euphorbia subgenus Chamaesyce, with special reference to bees. Am Midl Nat 101:87-98

Fægri K, van der Pijl L (1979) The principles of pollination ecology. Pergamon Press, Oxford

Fenster CB, Armbruster WS, Wilson P, Dudash MR, Thomson JD (2004) Pollination syndromes and floral specialization. Annu Rev Ecol Evol Syst 35:375-403

Fiala B, Maschwitz U (1991) Extrafloral nectaries in the genus Macaranga (Euphorbiaceae) in Malaysia: comparative studies of their possible significance as predispositions for myrmecophytism. Biol J Linn Soc 44:287-305

Fiala B, Meyer U, Hashim R, Maschwitz U (2011) Pollination systems in pioneer trees of the genus Macaranga (Euphorbiaceae) in Malaysian rainforests. Biol J Linn Soc 103:935-953

Irwin RE, Adler LS, Brody AK (2004) The dual role of floral traits: pollinator attraction and plant defense. Ecology 85:1503-1511 
Ishida C, Kono M, Sakai S (2009) A new pollination system: brood-site pollination by flower bugs in Macaranga (Euphorbiaceae). Ann Bot 103:39-44

Itioka T (2005) Diversity of anti-herbivore defences in Macaranga. In: Roubik DW, Sakai S, Karim AAH (eds) Pollination ecology and the rain forest: Sarawak studies. Springer, New York, pp 158-171

Johnson S, Linder H, Steiner K (1998) Phylogeny and radiation of pollination systems in Disa (Orchidaceae). Am J Bot 85:402-411

Kawakita A, Kato M (2009) Repeated independent evolution of obligate pollination mutualism in the Phyllantheae-Epicephala association. Proc Biol Sci 276:417-426

Kulju KKM, Sierra SEC, Draisma SGA, Samuel R, van Welzen PC (2007) Molecular phylogeny of Macaranga, Mallotus, and related genera (Euphorbiaceae s.s.): insight from plastid and nuclear DNA sequence data. Am J Bot 94(10):1726-1743

Lewis T (1973) Thrips: their biology, ecology and economic importance. Academic Press, London

Mackay DA, Whalen MA (1991) Some associations between ants and euphorbs intropical Australia. In: Huxley C, Cutler DF (eds) Ant-plant interactions. Oxford Univ. Press, Oxford, pp 238-249

Moog U, Fiala B, Federle W, Maschwitz U (2002) Thrips pollination of the dioecious ant plant Macaranga hullettii (Euphorbiaceae) in Southeast Asia. Am J Bot 89(1):50-59

Okuyama Y, Kawakita A (2012) DNA extraction protocol from plants (altered CTAB method). In: Kawakita A, Okuyama Y (eds) Biology of species interactions. Bun-ichi Sogo Shuppan Co., Tokyo, pp 273-278 [In Japanese]

Okuyama Y, Pellmyr O, Kato M (2008) Parallel floral adaptations to pollination by fungus gnats within the genus Mitella (Saxifragaceae). Mol Phylogenet Evol 46:560-575

Ollerton J, Winfree R, Tarrant S (2011) How many flowering plants are pollinated by animals? Oikos 120:321-326

Pagel M, Meade A (2006) Bayesian analysis of correlated evolution of discrete characters by reversiblejump Markov chain Monte Carlo. Am Nat 167:808-825

Pagel M, Meade A, Barker D (2004) Bayesian estimation of ancestral character states on phylogenies. Syst Biol 53:673-684

Proctor M, Yeo P, Lack A (2006) The natural history of pollination. Harper Collins, London

Quek S-P, Davies SJ, Itino T, Pierce NE (2004) Codiversification in an ant-plant mutualism: stem texture and the evolution of host use in Crematogaster (Formicidae: Myrmicinae) inhabitants of Macaranga (Euphorbiaceae). Evolution 58:554-570

Ronquist F (2004) Bayesian inference of character evolution. Trends Ecol Evol 19:475-481

Ronquist F, Huelsenbeck JP (2003) MrBayes 3: Bayesian phylogenetic inference under mixed models. Bioinformatics 19:1572-1574

R Development Core Team (2013) R: a language and environment for statistical computing. R Foundation for Statistical Computing, Vienna, Austria. http://www.R-project.org/

Sakai S, Kawakita A, Ooi K, Inoue T (2013) Variation in the strength of association among pollination systems and floral traits: evolutionary changes in the floral traits of Bornean gingers (Zingiberaceae). Am J Bot 100:546-555

Santamaría L, Rodríguez-Gironés MA (2007) Linkage rules for plant-pollinator networks: trait complementarity or exploitation barriers? PLoS Biol 5:e31

Tanabe AS (2011) Kakusan4 and Aminosan: two programs for comparing nonpartitioned, proportional and separate models for combined molecular phylogenetic analyses of multilocus sequence data. Mol Ecol Resour 11:914-921

Van der Niet T, Johnson SD (2012) Phylogenetic evidence for pollinator-driven diversification of angiosperms. Trends Ecol Evol 27:353-361

Whalen MA, Mackay DA (1988) Patterns of ant and herbivore activity on five understory euphorbiaceous saplings in submontane Papua New Guinea. Biotropica 20:294-300

Wheeler AG (2001) Biology of the plant bugs (Hemiptera: Miridae): pests, predators, opportunists. Cornell University Press, New York

Whitmore TC (2008) The genus Macaranga-a prodromus. Kew Publishing, Kew

Whittall JB, Hodges SA (2007) Pollinator shifts drive increasingly long nectar spurs in columbine flowers. Nature 447:706-710

Willmer PG, Stone GN (1997) How aggressive ant-guards assist seed-set in Acacia flowers. Nature 388:165-167

Wilson P, Wolfe AD, Armbruster WS, Thomson JD (2007) Constrained lability in floral evolution: counting convergent origins of hummingbird pollination in Penstemon and Keckiella. New Phytol 176:883-890

Wragg PD, Johnson SD (2011) Transition from wind pollination to insect pollination in sedges: experimental evidence and functional traits. New Phytol 191:1128-1140 
Yamasaki E, Kawakita A, Sakai S (2013) Modified leaves with disc-shaped nectaries of Macaranga sinensis (Euphorbiaceae) provide reward for pollinators. Am J Bot 100:628-632

Yamasaki E, Inui Y, Sakai S (2014) Production of food bodies on the reproductive organs of myrmecophytic Macaranga species (Euphorbiaceae): effects on interactions with herbivores and pollinators. Plant Species Biol 29:232-241 